\title{
E Agora Falamos Nós: M ulheres Beneficiárias do Bolsa Família em Redenção-CE.
}

Vera Rodrigues ${ }^{1}$

\section{Resumo}

Não é incomum ouvir-se nos espaços públicos ou privados manifestações preconceituosas contra as beneficiárias do Programa Bolsa Família. São comentários pejorativos que nomeiam essas mulheres como: "vagabundas" que agora não querem exercer o trabalho rural ou doméstico porque possuem o Bolsa Família; mulheres que só querem "fazer menino" (engravidar) e assim continuar vivendo "às custas do governo". Diante destas e outras questões como não pensar buscar desvelar a realidade vivida por essas mulheres? Como não questionar as rupturas e continuidades nas suas condições de vida para além da maternidade como parâmetro? Será a condição de "pobre" suficiente para informar-nos sobre a dinâmica social que as envolve? Instigadas por essas questões e pela problematização teórica entre gênero, raça/cor e classe social a autora juntamente com jovens pesquisadoras elaboraram e executaram o projeto de pesquisa "E agora falamos nós: mulheres beneficiárias do Bolsa Família em Redenção/CE”, o qual foi aprovado na CHAMADA № 24/2013 MCTI-CNPq/MDS-SAGI. Assim, emerge o presente artigo como resultado do projeto em foco, que tem como objetivo evidenciar a fala dessas mulheres em relação ao preconceito, pobreza, bem como suas percepções acerca do Programa Bolsa Família. 0 projeto de cunho qualitativo realizou entrevistas se-

1 Professora na UNILAB - Universidade da Integração Internacional da Lusofonia Afro-brasileira (Redenção - Ceará). Professora Adjunta lotada no Instituto de Humanidades e Letras. Doutora em Antropologia Social pela Universidade de São Paulo E-mail: vera. rodrigues@unilab.edu.br 
miestruturadas com setenta mulheres nordestinas no município cearense de Redenção.

Palavras-chave: Bolsa Família; Mulheres, Pobreza, Preconceito.

\section{N ow W e Speak: W omen Beneficiaries of the "Bolsa Família" in Redenção -CE, Brazil}

\section{Abstract}

It is not uncommon to hear in public or private spaces prejudiced demonstrations against the beneficiaries of the Bolsa Família Program. Derogatory comments are naming these women as "sluts" who now do not want to exercise or rural domestic work because they have the Bolsa Família; women who just want to "do boy" (pregnant) and thus keep living "at government expense." Given these and other issues like not thinking, seek to unveil the reality experienced by these women? How not to question the ruptures and continuities in their living conditions beyond motherhood as a parameter? Is the condition of 'poor' enough to inform us about the social dynamics that involve? Instigated by these issues and theoretical disputes between gender, race / color and social class the author along with young researchers, developed and implemented the research project "And now we speak: women beneficiaries of Bolsa Família in Redemption / CE", which it was approved in CALL No. 24/2013 MCTI-CNPq / MDS-SAGI. Thus emerges this article because of the focus on project, aiming to show the speech of these women in relation to prejudice, poverty, and their perceptions of the Bolsa Família Program. The qualitative study project conducted semistructured interviews with seventy women in northeastern Ceará municipality of Redenção.

Keywords: Bolsa Família; Women, Poverty, Prejudice 


\section{Entre a "N egra N ua" e as Beneficiárias do Programa Bolsa Família}

O Programa Bolsa Família surge com o viés da redução da pobreza por meio da transferência de renda. Esta transferência tem nas mulheres o seu agente principal, já que são elas as responsáveis por gerir esse recurso no âmbito familiar. 0 potencial do Bolsa Família pode ser mensurado pelo atendimento de 13 milhões de famílias no cenário nacional, bem como para o investimento orçamentário no PPA- Plano Pluri-Anual para o período 2012-2015, que prevê $\mathrm{R} \$ 84,260$ bilhões, o que representa $1,87 \%$ do total dos recursos alocados para os programas temáticos, ocupando o $14^{\circ}$ lugar em maior volume de recursos entre os 65 programas.

O conjunto desses dados nos leva a crer na boa estrutura de manutenção do PBF, bem como na sua eficácia em atingir o objetivo principal de combate e redução da pobreza. No entanto, nos cabe atentar também para os desafios que permanecem na consecução de um programa inédito no cenário das políticas públicas, bem como de ocorrer em um país com as dimensões territoriais e heterogeneidades regionais como o nosso. Isso tudo acrescido da perspectiva de enfrentamento das desigualdades de gênero, garantia de direitos e promoção da autonomia socioeconômica feminina.

É nessa perspectiva que o projeto "E agora falamos nós: mulheres beneficiárias do Bolsa Família em Redenção/CE” se enquadra e visa contribuir para a formulação de políticas públicas municipais e para a temática sobre desigualdades de gênero. Esse entendimento parte do cenário regional e local para buscar as suas bases e dinâmica processual. Assim, sabemos que em nível regional, segundo dados do "Observatório de Política para $\mathrm{Mu}$ lheres", a região nordeste, até junho de 2009, contava com 07 organismos estaduais de políticas para mulheres e 56 municipais, 
além de 22 conselhos municipais dos direitos da mulher, como órgãos formadores de uma rede de proteção social à mulher.

Essa rede encontra disparidades em termos microrregionais, como no caso do município de Redenção, o qual não possui um conselho municipal dos direitos da mulher. A inexistência do Conselho significa a ausência de um fórum específico para o debate, formulação e encaminhamento relativos às questões de gênero. Isso é algo que poderia receber incentivo para sua criação, a partir da produção de conhecimento sobre a realidade das mulheres "redencionistas". Essa realidade faz parte da cidade que comporta, de acordo com o censo do IBGE (2010), 26.423 habitantes, a maioria vivendo em área rural. Esse é o caso de Redenção, distante $60 \mathrm{~km}$ da capital Fortaleza. A cidade faz parte do Maciço do Baturité, região do sertão central cearense composta por treze municípios de pequeno porte.

Os dados disponíveis via CRAS - Centro de Referência de Assistência Social informa que as famílias cadastradas no CADÚNICO - Cadastro Único para Programas Sociais, até maio do corrente ano, perfaziam um total de 5.604, destas 3.820 famílias atendidas pelo Bolsa Família especialmente na área rural. Sobre as mulheres, os dados disponíveis limitam-se ao acompanhamento enquanto gestantes. Esse ponto vai ao encontro do que vem sendo questionado e debatido por movimentos feministas e intelectuais, de que a priorização da mulher pela ótica reprodutiva compromete olhares críticos sobre outras esferas da vida feminina, como educação, trabalho, além de contribuir para a manutenção de um padrão de relações de gênero pautado pelas desigualdades (Cfêmea, 2011).

Esse padrão das relações de gênero pode ser pensado tanto em nível regional quanto local. 0 nordeste do Brasil, enquanto uma sociedade fundada em parâmetros patriarcais, agrários, escravocratas e, portanto, marcado por relações sociais hierarquizadas, nos permite ter este quadro como algo a considerar 
quando falamos na situação social das mulheres. Localmente, a cidade de Redenção apresenta um quadro social instigante: aqui se deu o pioneirismo da libertação dos escravizados no período colonial. Em 1883, os 116 escravizados (as) da província teriam sido libertos pela conjugação de interesses de seus senhores e abolicionistas influentes. Depois disso, desapareceram. Essa é a versão oficial que embasa a memória coletiva e é usada como marco da historicidade redencionista. No entanto, o discurso local - o qual encontra eco no restante do Ceará - é que aqui não há "negros (as)" e os que existem são vistos e tratados como estrangeiros.

Nesse marco há uma figura feminina: a "Negra Nua”, um monumento na entrada da cidade no formato da imagem de uma mulher negra, nua, de joelhos, com as mãos erguidas para o alto como em agradecimento à liberdade recebida. Essa imagem está presente nas embalagens de produtos locais (doces e cachaça), sendo veiculada comercialmente. No entanto, vazia de historicidade. É uma imagem sem nome, sem referências, que perpassa apenas os limites do entendimento de que teria sido uma escravizada que ao deixar morrer o filho do seu senhor (devido a uma queda) teria sido mutilada (seio cortado) e, após, queimada e enterrada viva na senzala da casa-grande.

Trazer este dado ao projeto visa agregar um espaço crítico para essa e outras histórias sobre violências contra mulheres, as quais são, por vezes, silenciadas assim como podem estar sendo silenciadas, contemporaneamente, outras histórias de mulheres. Fazendo uma ligação disso com as beneficiárias do Bolsa Família, não é incomum ouvir-se nos espaços públicos comentários sobre quem são estas mulheres: "vagabundas" que agora não querem exercer o trabalho rural ou doméstico porque possuem o Bolsa Família; mulheres que só querem "fazer menino" (engravidar) e assim continuar vivendo "às custas do governo". Diante destas e outras questões como não pensar buscar desvelar a realidade vivida por essas mulheres? Como não questionar as rupturas e 
continuidades nas suas condições de vida para além da maternidade como parâmetro? Será a condição de "pobre" suficiente para informar-nos sobre a dinâmica social que as envolve?

Analisando o exposto acima, se estivermos de acordo que a pobreza é um fenômeno multidimensional, como já tratado em publicações de órgãos como o IPEA - Instituto de Pesquisas Econômicas e Aplicadas ${ }^{2}$ - então, torna-se operacionalmente interessante oferecer outras perspectivas para a definição de pobreza baseada única e exclusivamente na renda, sendo assim, como desconsiderar as categorias de raça/cor - se a pobreza tem cor no Brasil - que juntamente com a categoria gênero formatam o quadro da vulnerabilidade social a ser rompido, combatido via programas como o Bolsa Família.

Apoiadas na intersecção entre as categorias de gênero, classe social e raça/cor somadas ao quadro local na cidade de Redenção, o projeto "E agora falamos nós: mulheres beneficiárias do Bolsa Família em Redenção/CE” propôs um olhar multifacetado para as mulheres que compõem as famílias atendidas pelo Bolsa Família e que, de acordo com dados do CRAS, distribuem-se em termos de raça/cor como brancas (123); pretas (45); pardas (3753) e indígenas (01). Cabe ressaltar que o projeto incorpora as mulheres não só em relação aos sujeitos da pesquisa, mas também às bolsistas do projeto oriundas do curso de Bacharelado em Humanidades. Nesse perfil, o projeto contou com 04 (quatro) bolsistas CNPQ ITI-A: Maria de Fátima Souza da Silveira, Maria Valdylene Jacó da Silva, Nayana Camurça de Lima e Silmara Peixoto Moreira, e 03 (três) bolsistas voluntárias: Cristiane Freire Gomes, Jane Cleia Pereira da Costa e Tatiana de Lima Sousa.

O projeto foi desenvolvido entre março de 2014 e junho de 2015. Durante esse período realizamos encontros de formação teóri-

2 Ver: “Nota Técnica PNAD 2014 - breves análises” e “Comunicado do Ipea no 159”. 
co-metodológica; reuniões com gestores municipais do Bolsa Família; evento de lançamento do projeto para a comunidade acadêmica e não acadêmica (gestores, beneficiárias e interessados (as) na temática proposta). Ao fim realizamos a coleta e análise de dados resultantes de setenta entrevistas realizadas com mulheres beneficiárias e moradoras da sede do município de Redenção e área rural.

\section{Reflexões e Representações sobre Gênero, Raça/C or e Pobreza:}

Nas ciências sociais, especialmente na antropologia, há um campo de estudos denominado "marcadores sociais da diferença", em que se busca explicar como são constituídas socialmente desigualdades e hierarquias entre grupos sociais e indivíduos. Por marcadores da diferença, compreendem-se, por exemplo, as categorias de gênero, raça/cor, sexualidade e classe social. Tais categorias são percebidas pelo senso comum como naturais e autoexplicativas das relações sociais. Assim, quem já não ouviu dizer "isso é coisa de mulher", "pobre e preto nasceu para sofrer", dentre outras expressões daquilo que entendemos em um primeiro momento sobre isso.

Em um segundo momento, pode-se desconstruir essas percepções demonstrando que estas são fruto das relações sociais, da interação humana e não algo dado pela natureza. Torna-se interessante, também, agregar a perspectiva que nos traz Guimarães (2003) sobre categorias analíticas e nativas. Nessa distinção, o autor ressalta que a categoria analítica possibilita a análise de um determinado conjunto de fenômenos, e faz sentido apenas no corpo de uma teoria. Já uma categoria nativa possui sentido histórico e específico no mundo prático, efetivo de um determinado grupo social.

No entendimento de que as categorias de gênero e raça/cor possuem tanto um caráter analítico quanto nativo, nossa proposta é 
perceber como estas se interligam na análise multidimensional da pobreza. Para isso, vamos descortinar teórica e contextualmente essas categorias.

Em Schwarcz (1993) há o instigante debate sobre a unidade do gênero humano, gerador de controvérsias e teorias que fundamentaram a ideia de "raça". Por "raça", tem-se no século XIX, conforme a autora, a "ideia da existência de heranças físicas permanentes entre os vários grupos humanos", fundadas nas ciências naturais e que trazem uma imutabilidade biológica atuando como vetor da formulação de teorias raciais.

Tal debate é perpassado pela noção da diferença e da hierarquização social, as quais configuram visões que moldam paradigmas em épocas subsequentes. Nesse momento, o conteúdo biológico de "raça" é usado para explicar a vida social. Assim, fenômenos sociais como criminalidade, ou mesmo qualidades morais e intelectuais, são referendadas por essa noção e, ainda hoje, percebe-se no discurso nativo resquícios deste entendimento nas referências à "preguiça do baiano/nordestino", leia-se "preguiça do negro/preto", ou "empreendedorismo civilizador do gaúcho", leia-se "empreendedorismo do homem branco/ descendente de europeus".

Para entender o significado de raça, no século XXI, as ciências sociais no Brasil apoiam-se não mais no conceito morfobiológico do século XIX, mas naquilo que autores como Guimarães (2003) e Munanga (2004) enfatizam como discursos sobre as origens de um grupo, que usam termos que remetem à transmissão de traços fisionômicos, qualidades morais, intelectuais, psicológicas; Ou ainda raça como uma construção social, cultural e ideológica interligada às estruturas de poder, dominação e hierarquização entre grupos sociais. Essas ênfases "discurso" e "construção social" podem nos dizer algo sobre como "raça" opera na concretude dos dados sobre a afetividade entre a população negra. 
0 mesmo ocorre em relação à noção de "Cor", tratado por Guimarães (idem) como um difícil discurso classificatório sobre cores, pois totalmente nativo e naturalizado. Além disso, ressalta o autor, diferentemente de "raça", não há ampla literatura sobre usos e origem, a não ser quando aplicada a outros campos do conhecimento humano como artes e literatura. Porém, faz parte das formas como indivíduos se classificam e classificam os demais. Tomemos isso, em relação à expressiva quantidade de cores com que muitos brasileiros (as) se identificam: moreno (a), marrom-bombom, cor de cuia, dentre outras possibilidades demonstradas em pesquisas censitárias.

Enquanto as noções de "raça" e cor aparecem justapostas, na maioria das análises, o conceito de sexo foi sendo paulatinamente substituído por gênero, termo que surgiu no mundo acadêmico no momento em que pesquisadoras feministas buscavam desnaturalizar a condição da mulher na sociedade. Gênero foi um conceito construído socialmente na década de 70 buscando compreender as relações estabelecidas entre os homens e as mulheres, os papéis que cada um assume na sociedade e as relações de poder estabelecidas entre eles. Para explicitar que sexo social não é determinado pelo sexo biológico; ou seja, a sociedade imputa uma diferença cultural entre homem e mulher que resulta em uma cisão construída, independente, portanto, de determinações biológicas. O Pesquisador Simão (2000), ressalta que:

Neste momento era necessário encontrar conceitos que permitissem diferenciar aquilo que as mulheres tinham de normal, permanente e igual em todas as épocas e culturas (o sexo) daquilo que dava margem para discriminação e por ser socialmente construído, variava de sociedade para sociedade e podia mudar com o tempo (gênero). (Simão, 2000, p. 9).

Entre as várias definições, Scott (1990) destaca que gênero é um meio de decodificar o sentido e de compreender as relações 
complexas entre diversas formas de interação humana. Sua discussão sobre gênero é compreendida como:

Um elemento constitutivo de relações sociais fundadas sobre as diferenças percebidas entre os sexos (e como) um primeiro modo de dar significado às relações de poder. (Scott, 1990, p.15).

Gênero aqui é entendido como categoria, que na visão de Saffioti (2004), não se resume apenas a uma categoria de análise, é um conceito aberto, cuja investigação tem demandado muito investimento histórico, pois se refere a relações igualitárias e desiguais, representações do masculino e do feminino. Portanto, neste trabalho, gênero é visto como categoria de análise social. A autora Lavinas (1997) argumenta que no processo de socialização as categorias de gênero são permanentemente reconstruídas devido as interações que ocorrem nesse meio social, portanto, o gênero é uma das relações estruturantes que situa o indivíduo no mundo e ao longo da sua vida em relação a oportunidades, trajetórias, vivências e lugares.

Em paralelo aos conceitos de gênero e raça também atentamos para identidade. Este conceito vem sendo extensamente discutido através de autores como HALL (2002), compreendendo que ele preenche o espaço entre o interior e o exterior - entre o mundo pessoal e o mundo público. 0 fato de que projetamos a "nós próprios", nossas identidades culturais, ao mesmo tempo em que internalizamos seus significados e valores, tornando-os "partes de nós", contribui para alinhar nossos sentimentos subjetivos com os lugares objetivos que ocupamos no mundo social e cultural.

Trazemos aqui o conceito de identidade porque este se interliga a outro que nos é muito caro para este projeto de pesquisa: o de dignidade humana. Na dimensão da teoria do reconhecimento e multiculturalismo desenvolvido por Char- 
les Taylor e Axel Honneth, encontramos uma articulação conceitual em que sujeitos ou grupos sociais demandam na esfera privada ou na esfera pública o reconhecimento de sua dignidade humana, do seu pertencimento identitário. Antes de entender que reconhecimento é esse, cabe pensar no que estamos entendendo por dignidade humana e identidade na visão teórica dos autores.

Taylor nos traz um modelo procedimental em que a dignidade se resume aos direitos individuais, no tratamento igualitário em que Estado e sociedade convergem para a efetiva garantia destes direitos. Já a identidade surge como uma construção social, dialógica e que, portanto, requer um reconhecimento público, uma confirmação do outro. A ausência dessa confirmação na esfera intima ou do tratamento igualitário na esfera pública ferem a dignidade humana e podem se constituir em ofensa ou mesmo injustiça social. Isso porque o conceito de dignidade humana inspira-se na superação das hierarquias sociais impostas em regimes não democráticos para a composição da unicidade e humanidade dos sujeitos como parte/fundamento básico de Estados liberais democráticos. Sendo assim, a todos os cidadãos/ cidadãs deveria estar assegurado o respeito, a valorização de suas especificidades culturais nas sociedades democráticas, pois isto diz respeito às condições básicas da chamada "vida boa", o que no campo da ética se define como a vida feliz e justa vivida por todos os homens livres, Santos (2008).

Entende-se, assim, que um programa social como o Bolsa Família possui a dimensão do reconhecimento e da distribuição. Reconhecimento porque, ao fazer um estudo sobre e com mulheres no recorte do público-alvo beneficiário, estaria dialogando com a perspectiva da valoração da dignidade humana com base nas suas especificidades identitárias e culturais. Complementarmente, a distribuição aparece na ótica da renda que é transferida a esse grupo social e que lhe deve permitir acesso a bens, serviços e autonomia socioeconômica. 
Para alguns, a conjugação dessas dimensões gera uma tensão social, pois quando falamos em justiça e/ou políticas públicas, o que deve ser prioritário? Reivindicações de cunho específico, baseadas em identidades étnicas, sexuais ou religiosas, as quais não podem ser universalizadas, estendidas à sociedade como um todo? Ou reivindicações de igualdade social, as quais pela sua universalidade, não ferem princípios de uma ordem legal instituída, como aquela contida na constituição que diz que somos todos iguais perante a lei independente de gênero ou raça/cor?

Para fugir desse dilema, a ótica que Fraser (2007) oferece é interessante, porém, como a própria autora reconhece, é preciso alinhar a cada contexto ou caso, pois não há uma "receita pronta". A alternativa proposta é um conceito amplo de justiça que englobe tanto o reconhecimento quanto a distribuição. Para isso, a autora rompe com o modelo padrão de reconhecimento à identidade, pois entende que há uma ênfase demasiada na estrutura psíquica em detrimento das instituições sociais e interação social, além de impor uma identidade de grupo singular, o que acarretaria uma negação da heterogeneidade interna dos membros e a reificação da cultura.

Fraser, quando rompe com o modelo de identidade, propõe em seu lugar, o modelo de "status social" no qual o reconhecimento é deslocado da identidade para a "condição dos membros do grupo como parceiros integrais na interação social". Nesse deslocamento, o que está em jogo não é a depreciação de uma identidade, mas a negação de participação igualitária na vida social, a qual poderá ser superada com uma política que examine os "padrões institucionalizados de valoração cultural em função dos seus efeitos sobre a posição relativa dos atores sociais".

Isso significa dizer que a subordinação dos sujeitos no processo de interação social seria um efeito de valores culturais institucionalizados que demarcam lugares de inclusão/exclusão, visibilidade/invisibilidade social. A política de reconhecimento 
nesse caso seria uma questão de justiça. A promoção do status garantiria uma paridade social. Pois bem, nesse ponto podemos nos perguntar se e como o Programa Bolsa Família alteraria o status social de suas beneficiárias nos processos de interação social familiar e público.

Esse questionamento é tributário de estudos que vêm problematizando as condições de vida de mulheres beneficiárias do Bolsa Família. Em Suarez e Libardoni (2007), as pesquisadoras analisaram o programa, tendo como universo de pesquisa o cotidiano familiar e público de mulheres em 10 municípios entre as regiões sudeste, norte e nordeste. 0 ponto de partida analítico foi o reconhecimento da: "baixa condição social das mulheres, particularmente das não-brancas (indígenas, pretas e pardas), restringe severamente a segurança delas e de suas famílias e de que o Programa Bolsa Família é, na atualidade, a política mais significativa do sistema de proteção social do Brasil”.

Já em Rego e Pinzani (2013), a análise recai sobre a situação de submissão das mulheres e, consequentemente, da falta de autonomia para gerir suas próprias vidas, que se agrava ainda mais quando se trata de mulheres que se encontram em situação de extrema pobreza. A importância do programa se dá justamente por possibilitar, a partir do recebimento de uma renda regular, um início de uma autonomia que ocorrerá mesmo que em um processo lento, e isto associado ao fato do cartão do programa ser no nome da mulher que, segundo os autores, é um fato considerado positivo pela quase totalidade delas e por motivo evidente: elas seriam melhores gestoras da economia doméstica e de que "os maridos seriam incapazes de fazer compras adequadas às necessidades familiares ou gastariam o dinheiro em bebidas".

(...) podemos afirmar que um programa de transferência estatal de renda a mulheres pobres como o Bolsa Família se insere em uma ainda incipiente política pública de cidadania. $O$ fato de ainda ser muito insuficiente como tal não nos 
permite ignorar suas possibilidades de se tornar uma consistente política de formação de cidadãos, se complementadas por um conjunto mais amplo de políticas que visam a esse alvo garantido na constituição de 1988. Nesse sentido, o BF começa pela preliminar de todas as prerrogativas da cidadania, porque diz respeito ao mais preliminar direito, o direito à vida. (Rego; Pinzani, 2013, p. 168).

Nessa leitura, a pobreza é um problema bastante complexo e, portanto, não deve ser analisado apenas do ponto de vista econômico, este é apenas um dos possíveis âmbitos de análise, embora seja o de fundamental importância. É preciso abordar outros critérios para definir quem é pobre no Brasil, critérios estes que podem ser: a cor da pele, o gênero, a classe social e a região e área em que vivem. As diferenças nos modos de vida e de dificuldades enfrentadas por pobres urbanos e rurais são claras, os últimos enfrentam quase sempre o problema de acesso aos serviços básicos, como saúde e educação, além da falta de oportunidade de emprego, que nessas áreas é quase nula, existindo apenas a opção da agricultura, mas que em tempos de secas se faz quase impossível, caso da área rural de Redenção.

Os hospitais quase sempre se encontram na área urbana sendo necessária uma locomoção, como por exemplo, no caso local, no qual as comunidades que vivem nas áreas rurais (denominadas "serras") dispõem apenas de um posto de saúde com consultas mensais, e sem emergência. Quando é necessária uma intervenção cirúrgica, por exemplo, tem que se recorrer a sede e muitas vezes à Fortaleza. Na educação, os alunos têm que se deslocar de uma serra a outra para que possam estudar, isto, muitas vezes, em veículos com péssimas condições de transporte.

Esses fatos servem para salientar, conforme Rego e Pinzani (2013), a operação ideológica voltada à naturalização da pobreza no Brasil: a ideia de que esta seja uma espécie de fenômeno natural imutável, contra o qual qualquer luta é inútil, esconde muitas coisas, além, claro, do interesse em manter o status quo 
social, político e econômico. As operações ideológicas com as quais se naturaliza a pobreza chega a abertas contradições, porquanto, ao mesmo tempo em que se afirma a diversidade quase antropológica do pobre, se exalta a presumida democracia racial, como em Gilberto Freyre. Assim, as luzes jogadas por esses e outros estudos nos impele a contribuir pelo viés analítico com a problemática das desigualdades que o tripé pobreza/gênero/ raça nos desafia.

\section{A teoria vivida no desenvolvimento do projeto "E agora falamos nós, mulheres beneficiárias do Bolsa Família: Redenção/CE". ${ }^{3}$}

Aqui tomamos emprestada a reflexão da antropóloga Mariza Peirano (2006), em que esta destaca o par inseparável constituído pela teoria e etnografia, em que a perspectiva teórica emerge também no dia a dia acadêmico, em sala de aula, na orientação de um aluno (a) e, no nosso caso, na elaboração e execução de um projeto de pesquisa. Assim, aqui, mais do que expor os passos metodológicos do projeto, está presente a "teoria vivida" que entrelaçou diálogos, ideias e expectativas, que irão também se desdobrar no trabalho de campo com mulheres beneficiárias do Programa Bolsa Família. Tudo começou em março de 2014 quando realizamos o processo seletivo para bolsistas. A seleção teve como critérios a análise de carta interesse dos candidatos (as); índice de desenvolvimento estudantil (média da nota acadêmica) e entrevista.

0 projeto recebeu a candidatura de 13 (treze) alunas (os) oriundas (os) dos cursos de graduação Bacharelado em Humanidades e Licenciatura em Letras. Houve um interesse maior de jovens mulheres representado pelo número de 11 (onze) 
universitárias com idades entre 18 e 23 anos. Este fato foi gerado pela identificação com o tema do projeto - Bolsa Família - já que algumas se identificaram como filhas e/ou parentes de beneficiárias e, viram na articulação entre a abordagem de políticas públicas e recorte de gênero, uma instigante análise, já que parte delas participavam de grupos de estudo e/ou pesquisa com estas pautas.

Nesse processo seletivo foram selecionadas 04 (quatro) estudantes como bolsistas CNPQ e 03 (três) bolsistas voluntárias. A opção por também contar com bolsistas voluntárias partiu do interesse demonstrado pelas jovens e a busca por oportunizar a um grupo maior a vivência e o aprendizado no âmbito da iniciação científica. Isso ocorreu ao longo de encontros quinzenais para formação teórico-metodológica; planejamento e organização do campo e, finalmente, socialização dos resultados com a comunidade acadêmica, beneficiárias e gestores do Programa Bolsa Família no município de Redenção.

Sobre as entrevistas cabe dizer que as primeiras tiveram o caráter de experiência piloto e foram realizadas com as beneficiárias que compareceram ao evento de lançamento do projeto. Essas entrevistas foram feitas em duplas e seguiram as redes de contato estabelecidas nas redes de sociabilidade local (igrejas, feiras, associações comunitárias, etc.). Em relação ao instrumento de coleta de dados, nós finalizamos um roteiro de questões, assim composto: 05 questões fechadas a serem preenchidas pela bolsista que realizaria a entrevista com vistas a traçar um perfil geral de nossas entrevistadas. Na segunda parte, um roteiro de perguntas abertas em que se buscava ouvir as nossas interlocutoras, por meio de um diálogo registrado em áudio com o aceite das interlocutoras. Acordamos que cada bolsista realizaria 10 (dez) entrevistas entre os meses de agosto e outubro. Entre os meses de novembro e março de 2015 houve a elaboração e entrega das relatorias das bolsistas. Nos meses subsequentes, até junho, realizamos a análise dos dados coletados em campo. 


\section{E agora falamos nós: mulheres beneficiárias do Bolsa Fa- mília em Redenção/CE}

Se há muitas Severinas ${ }^{4}$ no sertão do Piauí também há muitas Marias no sertão cearense. Aqui encontramos Angela Maria, Maria Consolação, Maria das Graças, Maria José, Maria Estelina, Marcia Maria, Maria Liduína, Maria Nair, Maria Zenita e tantas outras que nos emprestaram suas falas". Assim como as "Marias", muitos são os lugares do sertão central onde vivem: elas vêm das serras de Piroás, Verde e Olho D’agua. Dos distritos de Outeiro e Antonio Diogo, bem como da cidade de Redenção e arredores conhecidos como Beco Santo Antônio e Boa Fé. São trabalhadoras rurais ${ }^{6}$, empregadas domésticas, donas de casa e mães na faixa etária entre 25-50 anos de idade, com ensino fundamental incompleto e que se reconhecem, em sua maioria, como pardas.

São mulheres que nos dizem: “(...) eu não tive essas infância boa não”, “(...) eu trabalhei muito assim em casa de família, sofri muito, aí graças a Deus né, agora eu estou mais feliz!" ou "(...)A minha mãe era evangélica, a gente só saía pra igreja. A minha vida de criança e de jovem foi essa. E depois de casada só tomando de conta da casa e trabalhando, só isso... não tem nada assim que marcasse muito não..."; "Ah... a minha infância assim, foi muito difícil né, porque antigamente não tinha o Bolsa Família, meu pai tinha que comprar uns cadernos, ele tinha que comprar o material escolar da gente né; farda, sapato, essas coisas..."

As primeiras falas são permeadas de momentos de silêncios, alguma timidez e memórias vivas sobre o trabalho familiar na

4 Em referência ao documentário "Severinas: as novas mulheres do sertão" da cineasta Eliza Capai.

5 A fim de preservar a identidade das nossas interlocutoras nomeamos todas como "Marias". 6 Muitas fazem pequenas plantações em seus quintais e pagam o sindicato de trabalhadores rurais, para futuramente garantir a sua aposentadoria. 
roça; as feiras de domingo com gosto de rapadura e das dificuldades de acesso à escola. Na sequência, as falas recaem sobre as mudanças que a vida trouxe: filhos, casamentos e expectativas futuras. Nessas trajetórias de vida aparece o "dinheirinho que ajuda a gente assim" e faz "a vida melhor". Observa-se que são "Histórias muito parecidas, mas que continham um quê especial em cada uma, cada qual conta do seu jeito" como relatou a bolsista Tatiana Souza em seu diário de campo. Esse "quê especial" traduz-se nos relatos ${ }^{7}$ a seguir, sobre o Bolsa Família:

Ave Maria, o Bolsa Família melhorou muito, melhorou muito mesmo, na vida da... da pessoa, porque com esse dinheiro é que a pessoa consegue... viver, comprando alguma coisa. No tempo que não tinha esse Bolsa Escola, ave Maria, a gente sofria muito. (Maria, 38, 3 filhos)

Ah... na minha infância, eu trabalhei muito assim em casa de família, sofri muito, aí graças a Deus né, agora eu estou mais feliz porque... não ganho nada assim de esposo né, mas o Bolsa Família me ajuda muito quando eu preciso pagar um exame, uma coisa, o Bolsa Família é que me ajuda. Triste se não fosse ele pra me ajudar né... em alguma coisa né. (Maria, 51, 3 filhos)

[...]pra mim foi uma grande ajuda que o governo criou para as famílias necessitadas. (Maria, 25 anos, um filho, solteira, estudante universitária).

Sei que vou ter aquele dinheiro todo mês, eu vou ter aquele tanto, então se tiver um gasto, já sei que posso contar com aquele dinheiro. (Maria, 22 anos, uma filha de 3 anos)

Ficou melhor porque a pessoa sabe que tendo os filhos na escola a pessoa tem, se eles querem um caderno a gente tem pra comprar, uma chinela, tudo isso a gente tem né. Aí melhorou mais....Pago água, pago luz, pago um gás, faço umas compras pra casa, pronto...é pra isso aí, pra casa. (Maria, 46, seis filhos)

7 Trechos de relatos colhidos pela bolsista Nayana Camurça. 
Entre as entrevistadas havia mulheres que recebiam o benefício há três meses e até uma década. Isso nos possibilitou perceber que, independente da linha de tempo entre elas, havia a percepção comum de um "antes" e "depois" na vida de cada uma, a partir da condição de beneficiária. Essa condição lhes permite a segurança advinda de uma renda fixa. No seu trabalho de conclusão de curso a bolsista Fátima Silveira avalia que:

Em uma situação onde há ausência de quase tudo, carência de quase tudo, uma renda fixa, mesmo que pouca ou insuficiente já é capaz de provocar mudanças significativas na vida de uma família. Rego e Pinzani (2013) destacam o PBF exatamente por este destinar uma renda monetária regular, o que segundo os autores possibilitam, mesmo que esta seja uma constatação ainda incipiente, que sejam iniciados processos de "libertação" das necessidades "prementes" à manutenção da vida. (Silveira, 2014, p. 60).

Essa maior segurança em ter seu próprio dinheiro aparece em algumas falas:

Porque eu sei que vai chegar aquele dia e eu vou ter, né.. (Maria, 22, um filho).

E eu sou separada, e... e nem um dos pai deles, nunca deram nada, nunca assumiram né, aí o pai quem ajudou, aí depois veio o Bolsa Família foi quem me ajudou mais ainda né pra poder botar eles pra estudar, ter uma coisa mais facilidade pra eles aprender alguma coisa. Aí eu tô aí... tô recebendo é, é uma coisa que é por mês, mas serve né, pra gente comprar o material escolar, farda, essas coisas que a gente precisa, alimentação né. (Maria, 45, 3 filhos).

É a primeira vez..., porque antes eu não pegava dinheiro na minha mão pra mim comprar nada. (Maria, 52 anos, viúva, 3 filhos).

A possibilidade de gerir o próprio dinheiro, ainda que seu gasto esteja vinculado às despesas familiares e não próprias, aponta 
para aquilo que a socióloga Walquíria Leão Rêgo e o filósofo Alessandro Pinzani (2013) indicam como um processo de (re) construção e fortalecimento da cidadania, para a garantia de melhor qualidade de vida, e, sobretudo, para a promoção da autonomia individual. Nesse sentido, existem diferentes dimensões da autonomia: família, trabalho, a capacidade de reagir em situações de violência, assim como sobre a possibilidade de gerir sua própria vida, já que se encontram muitas vezes em situação de submissão, agravada pelo fato de serem mulheres pobres. A importância do programa se dá justamente por possibilitar a partir do recebimento de uma renda regular, um início de uma autonomia, possibilitando assim que elas possam se libertar de condições familiares de opressão e violência (Cohn, 2013). É necessário ressaltar que esse processo é lento e ainda incipiente.

Essa ressalva visa apontar que essa autonomia ainda não é algo plenamente reconhecido pelas beneficiárias, na medida em que estas ainda entendem o Bolsa família como uma "ajuda" e não um direito social na ótica da cidadania. No entanto, não dá para dizer que as beneficiárias não percebam que existe certa rede de "ajuda" que impacta favoravelmente nas suas vidas. É assim quando elas mencionam a importância de outros programas sociais como Bolsa Escola, Água para Todos e Bolsa Estiagem. Outro dado, que nos faz refletir sobre o tema da autonomia, veio com o caso de uma jovem beneficiária cuja mãe também foi beneficiária. Por um lado, temos uma continuidade na necessidade do benefício para duas gerações de mulheres. Por outro, a jovem avança no processo de construção de uma autonomia ao se tornar universitária e projetar pela via da educação melhores condições de vida, as quais sua mãe não teve acesso.

Em outra dimensão de suas vidas, no caso, a relação com seus companheiros, este avanço mostra alguns sinais: 
eu posso ajudar ele na renda dentro de casa. (Maria, 35, 3 filhos).

Graças a Deus que sim né, assim, quando eu preciso assim de uma coisa, não precisa tá adulando marido pra me dar né, sempre eu vou controlando né, pra necessidade né. (Maria, 51, 3 filhos).

(risos) Mudou assim porque se ele não tá com condições de comprar eu tiro aquele bolsa família, já é uma mudança porque tô com condições de comprar né, aí é uma mudança aí, porque se ele não tem serviço, não tá com condições de comprar aquela coisa pra dentro de casa, eu tendo o bolsa família eu compro pra dentro de casa. (Maria, 46, 6 filhos).

(...)É assim, como eu tô dizendo, o meu eu vou logo pro mercantil e gasto todo lá, compro todo de merenda e coisa pros menino. Porque o pai deles tem outra família, ele só me dá duzentos e cinquenta, por mês. Aí com isso aí não dá, tem gente, tudo bem essa casa aqui é no meu nome por causa de segurança dos menino, mas isso que tô dizendo aqui é a verdade, é só isso aí que ele dá. E eu me viro com alguma coisinha e pronto (Maria, 43, 4 filhos).

O dinheiro obtido permite que elas não precisem "adular" marido ou mesmo contar unicamente com aquilo que o companheiro "põe dentro de casa". Assim, nesse processo, também se insere um certo empreendedorismo dessas mulheres quando elas buscam formação profissional em alguma atividade que lhes possibilitem um rendimento extra.

\section{O trecho abaixo extraído do diário de campo da bolsista Silmara Moreira retrata uma dessas situações:}

Maria* parecia tímida, mas tinha estampado em seu rosto a alegria de estar fazendo aquilo que gostava, dava para perceber o prazer que ela tinha de fazer unhas. Ela ficou um pouco restrita para falar da sua vida pessoal, mas conversando um pouco com ela, aos poucos ela foi me falan- 
do da sua vida, porém não quis falar da sua vida antes do Programa e sim depois o que eu achei muito interessante. Ela tinha prazer em falar porque estava trabalhando de manicure, e como o Bolsa Família lhe ajudou nesse sentindo, pois, o curso que ela tinha feito era destinado para as mulheres beneficiárias no município, provido pela antiga gestão. Então deixei ela a vontade para falar (...) ela me apresentou a sua filha mais velha que estava na sala com a gente, ela também estuda na Unilab no curso de Ciências da Naturezas e estar grávida do seu 1 o filho. (..) Ela mencionou um outro filho que estar inserido no programa Bolsa Atleta do Munícipio onde os meninos recebem ajuda de 100,00 reais para praticar futebol. Maria * disse que acreditava que esses Programas eram um direito do aluno, e que existia para ajudar e dar condições para esses alunos estudarem. E que o bolsa família era a continuidade do Bolsa Escola, que veio para ajudar os alunos. Há 12 anos ela recebe o Programa e disse que ele foi fundamental não só para seus filhos, mas para ela que hoje tem uma profissão por incentivo do Programa que proporcionou que ela fizesse o curso de manicure e hoje a maior parte da sua renda é por intermédio do seu trabalho. Hoje ela se sente realizada apesar de sempre ter trabalhado para ter seu dinheiro, ela falou que sempre quis aprender algo que ela quisesse tanto, uma profissão que ela realmente tivesse prazer em faze-la e ela encontrou essa realização sendo manicure.

A conquista de espaços de trabalho tem se revelado na perspectiva dessas mulheres um fator de orgulho pela conquista e um contraponto ao estereótipo de que as beneficiárias não querem trabalhar.

Eu acho assim, esse projeto veio pra ajudar, mas quando a pessoa estiver já bem estabilizada, logicamente procurar um trabalho, um emprego e deixar pra aqueles que já estão né... que vão necessitar do Bolsa Família realmente, ou que tão necessitando do Bolsa Família realmente, porque até a gente , tem até comentário que tem gente que recebe sem necessidade, né, a gente vê muito esses comentários por aí 
também, deixa de trabalhar porque tem, recebe dinheiro, e num é assim, eu acredito que não seja assim. (Maria, 35, 3 filhos).

(Indignada) Tem muita gente que não trabalha porque não tem emprego, a pessoa que não sabe ler eles não vão querer, a pessoa que são idoso também não vão querer eles só querem as pessoas que pera acaso que saiba muito ler, eles não querem uma pessoa pobre que não saiba ler, eles num querem não. (Maria, 52* viúva, 3 filhos).

(...)Eu não vejo dessa forma, pelo contrário, isso aqui é uma ajuda[...] se a gente for pensar só no bolsa família não vai dá pra manter a casa. Essas pessoas que pensam assim deviam dar um emprego pras outras pessoas, já que pensam assim, ajudar né. (Maria, 26, uma filha de 2 anos).

Para muitas delas o desejo de trabalhar permanece vivo. Para isso consideram que é preciso "terminar os estudos", já que isto é atualmente exigência comum. Em todas se observa um incômodo muito grande com os discursos que as chamam "ignorante" e/ou "vagabunda”. Para Silveira (2014), a expressão de seus rostos mudava imediatamente, dando a perceber o constrangimento que sentiam. Quando o assunto são os filhos respondem que "sem bolsa família ou com bolsa família, meu filho vai estudar". Querendo dizer que para elas era muito importante que seus filhos estudassem para melhorar de vida e assim ter oportunidades que não tiveram. A maioria não pretendia ter mais filhos, só "se Deus mandasse".

Quanto ao uso do Bolsa Família como mecanismo eleitoral e aí a conotação de que trocam voto por "esmola do governo", geralmente, se posicionam de forma contrária ou não têm opinião sobre isto.

(...) não, acho que não é compra de voto. Eu acho que isso aqui é uma ajuda que o governo dá, mas não seja em troca de voto não, porque cada qual tem que fazer por si né, tem que fazer por merecer, porque se não fizer por merecer também... e é assim, do jeito que o povo fala mesmo. Tem 
gente que fala que: - ai depois que teve esse Bolsa Família, aumentou a vagabundagem, não seio o quê... mas não, eles faz é porque quer, não é por causa do Bolsa Família não. Não trabalha é porque não quer. (Maria, 43, 3 filhos).

A pobreza é vista como um fato concreto em suas vidas. No entanto, isso não é justificativa para o preconceito, pois segundo dizem:

Pobreza é você amanhecer o dia e não ter nada pra comer dentro de casa, não é? (Maria, 51, 3 filhos).

(...) pobreza, eu acho que é aquele que num recebe o Bolsa Família, não tem emprego, não tem nada, aí é a pobreza mesmo né, porque tem muitos que recebem o Bolsa Família, mas mesmo assim ainda é pobreza, porque casa que tem muita gente pra cem, cento e pouco, isso aí não vale nada não. (Maria, 43, 4 filhos).

Eu acho que é fome né, não ter o que comer dentro de casa né, não poder comprar nada, se pede uma coisa não pode comprar acho que é isso aí. (Maria, 38, 2 filhos).

[...]É humilhante saber que a gente está dentro dessa estatística, não é nada agradável na verdade é humilhante, mas o que compensa no caso, o que faz a gente baixar a cabeça e engolir isso aqui é porque realmente ajudou. (Maria, 46, dois filhos).

Ser pobre, nessas circunstâncias, é uma linha tênue entre o sentimento de humilhação e o reconhecimento de que isto fere a dignidade humana. Ora, "não ter o que comer quando amanhece o dia" é a simbologia da ausência de perspectivas para aquele dia e outros que virão. Isso vai além de uma ideia de superação individual como força motriz para mudar de situação, ou seja, o sujeito é pobre porque "não se esforçou o bastante e que, portanto, é pobre por sua culpa", (Silveira Netto e Azzoni, 2013, p. 63). Este é um pensamento típico da ideologia meritocracia, que enxerga somente o indivíduo separado de seu contexto social e atribui somente a ele o mérito de ter vencido ou a culpa por ter fracas- 
sado, isentando a sociedade e o estado da responsabilidade na construção e reprodução das desigualdades e legitimando que nenhuma ação seja realizada objetivando resolver tal problema, o que o agrava e aprofunda cada vez mais e mantém a sociedade brasileira exatamente ainda injusta e desigual.

Diante disso, a importância de programas de transferência de renda associado ao crescente protagonismo feminino apontam para horizontes mais amplos de conquista e garantia de direitos humanos. As "Marias" com quem dialogamos não são meras estatísticas inseridas em gráficos e tabelas, mas pessoas reais com vidas que nos dizem muito sobre temas cruciais para a sociedade brasileira. Por conta disso, o projeto e artigo, que agora concluímos, não é uma porta que encerra um debate, mas uma janela que se abre para novos e promissores diálogos. Assim esperamos. Nós e as Marias do sertão central cearense.

\section{Considerações Finais}

$\mathrm{Na}$ análise das entrevistas com as beneficiárias do programa Bolsa Família ainda não é visto como um direto social, mas como uma "ajuda", e que dava mais "segurança", que antes do programa passavam muita "necessidade". Por conta disso, entende-se que ainda é preciso investir no tema da cidadania e direitos das mulheres. No tocante às relações de gênero, boa parte dos depoimentos enfatizou que o PBF não havia trazido mudanças para a relação do casal, a não ser o fato de que agora elas os ajudavam com as despesas da casa. No entanto, também ressaltaram que sentiam orgulho de dizerem que agora elas podiam comprar as coisas de casa, que elas cuidavam desse dinheiro.

A noção de pobreza esteve associada ao não acesso a bens de consumo. Algumas das respostas passavam sempre pela questão de querer comprar uma coisa e não poder; precisar de algo e não ter, outras também citaram a fome. Essa interface aponta que a 
possibilidade de gerir o próprio dinheiro vem alinhada com a decisão sobre o que consumir, ou seja, ter escolhas. Isso remete ao tema da dignidade humana, a qual está presente em atos do cotidiano como decidir sobre suas necessidades e vontades.

Em relação ao Programa Bolsa Família, quando questionadas se já haviam ouvido alguma coisa que não tinham gostado ou não concordavam a respeito do programa, na maior parte dos casos, se referiram ao valor do benefício, que ouviam que era baixo, mas que apesar de concordarem com isto acreditavam que as pessoas deveriam agradecer ao invés de reclamar. Outras também citaram a questão de que umas recebiam mais que a outras, revelando algumas tensões geradas no contexto dos valores recebidos.

Sobre o tema do preconceito contra as beneficiárias, a maioria identificou o estereótipo de que elas não queriam mais trabalhar para receber o benefício. Ressaltaram que o "sonho" era conseguir um emprego e terminar os estudos. Em todas, observou-se um incômodo muito grande com as adjetivações de "ignorante" e "vagabunda" oriundas dos discursos preconceituosos. A autoidentificação como "pardas" reflete a já esperada categorização usual no contexto. Isso também reflete o perfil populacional nos programas sociais, em que pretos e pardos perfazem a maioria. Sendo isso um indicativo da dinâmica entre pobreza e raça/cor, a qual ainda cabem maiores estudos.

Outro ponto a ser destacado diz respeito ao número de filhos. Algumas citaram algo interessante: "sem bolsa família ou com bolsa família, meu filho vai estudar". Isso indica que para elas era muito importante que seus filhos estudassem para melhorarem de vida e assim ter oportunidades que elas não tiveram. A maioria não pretendia ter mais filhos, só "se Deus mandasse". Isso corrobora a recente Pesquisa Nacional por Amostra de Domicílios (Pnad-2015) do IBGE - Instituto Brasileiro de Geografia e Estatística sobre a estabilidade no número de filhos entre as beneficiárias do PBF, contrariando a pré-noção de estímulo 
ao aumento do número de filhos ocasionada por programas de transferência de renda.

As expectativas futuras passam pelo acesso à educação para os filhos e para elas mesmas, demonstrando que a transversalidade das políticas públicas, entre por exemplo transferência de renda e acesso à educação, possui um potencial a ser avaliado na elaboração, execução e avaliação das mesmas.

\section{Ref erências Bibliográficas}

CASTRO, Josué. Geografia da Fome. Rio de janeiro, Civilização Brasileira, 1946.

CFEMEA: Centro Feminista de Estudos e Assessoria. Jornal Fêmea "Bolsa Família não leva em conta a autonomia das mulheres" - Ano XIV - n 171 - Brasília/DF - outubro/novembro/dezembro - 2011.

CAMPELLO, Tereza. CÔRTES, Marcelo Neri. (Organizadores) Programa Bolsa família uma década de inclusão e cidadania. / Brasília, P. 71-72, 2013

FRASER, Nancy. "Reconhecimento sem Ética?" Lua Nova: Revista de Cultura e Política [on line], São Paulo, 70:101-138, 2007 Disponível em: www.scielo.br Acessado em 10 jun 2011

GUIMARAES, Antonio Sérgio Alfredo. Como trabalhar com "Raça" em Sociologia. Educação e Pesquisa, São Paulo, v.29, n.1, jan/jun. 2003, p. 93-107.

HALL, Stuart. A Identidade Cultural na pós-modernidade. Rio de Janeiro: DP\&A: 2002.

LAVINAS, Lena. "Gênero, cidadania e adolescência." In: MADEIRA, Felícia Reicher (Org.). Quem mandou nascer mulher? Rio de Janeiro: Record/Rosa dos Tempos, 1997.

MUNANGA, Kabengele. Uma Abordagem Conceitual das Noções de Raça, Racismo, Identidade e Etnia. In: MUNANGA, Kabengele (org.). Cadernos PENESB (Programa de Educação sobre o Negro na Sociedade Brasileira), Universidade Federal Fluminense, Centro de Estudos Sociais Aplicada da Faculdade de Educação, no 5, 2004.

PEIRANO, Mariza. A Teoria Vivida: e outros ensaios de antropologia. Rio de Janeiro, Jorge Zahar ed., 2006. 
REGO, Walkiria; PINZANI, Alessandro Pinzani. Vozes do Bolsa Família: Autonomia, Dinheiro, e cidadania São Paulo: Editora Unesp, 2013.

SAFFIOTI, Heleieth Iara Bongiovani. Gênero, Patriarcado, Violência. 1a. ed. São Paulo: Editora Fundação Perseu Abramo: 2004.

SANTOS, Gislene Aparecida. Reconhecimento, utopia, Distopia: os sentidos da política de cotas raciais. Tese de livre docência apresentada à Escola de Artes, Ciências e Humanidades da Universidade de são Paulo, São Paulo, 2008.

SCHWARCZ, Lilia Miritz. O espetáculo das Raças: cientistas, instituições e questão racial no Brasil 1870-1930. São Paulo, Cia das Letras, 1993.

SCOTT, J. A Gênero: uma categoria útil para os estudos históricos? Educação e Realidade, Porto Alegre, v. 16, n. 2, p. 5-22, dez. 1990.

SILVEIRA NETO, Raul; AZZONI, Carlos. O Programa Bolsa Família e a Recente Queda da Desigualdade Regional de Renda no Brasil. Brasília: IPC-IG, no 229, novembro, 2013.

SIMÃO, Daniel Schroter. Gênero no mundo do Trabalho. MIMEMO, 2000. P 9.

SUAREZ, Mireya \& LIBARDONI, Marlene. O Impacto do Programa Bolsa Família: mudanças e continuidades na Condição Social das Mulheres, p.119-159. In: Avaliação de políticas e programas do MDS: resultados: Bolsa Família e Assistência Social. / Ministério do Desenvolvimento Social e Combate à Fome; Secretaria de Avaliação e Gestão da Informação - Brasília, DF: MDS; SAGI, 2007.

TAYLOR, Charles. Multiculturalismo. Instituto Piaget, Lisboa, Portugal, 1994. (Tradução Marta Machado. Coleção Epistemologia e Sociedade).

Recebido em 20/01/2016

Aprovado em 20/05/2016 